\title{
Isomerization and aggregation of 2-(2-(2-hydroxy-4-nitrophenyl)hydrazono)-1- phenylbutane-1,3-dione: recent evidences from theory and experiment
}

Hristova, Silvia; Kamounah, Fadhil S.; Crochet, Aulien; Hansen, Poul Erik; Fromm, Katharina M.; Nedeltcheva, Daniela ; Antonov, Liudmil

Published in:

Journal of Molecular Liquids

DOI:

10.1016/j.molliq.2019.03.073

Publication date:

2019

Document Version

Peer reviewed version

Citation for published version (APA):

Hristova, S., Kamounah, F. S., Crochet, A., Hansen, P. E., Fromm, K. M., Nedeltcheva, D., \& Antonov, L. (2019). Isomerization and aggregation of 2-(2-(2-hydroxy-4-nitrophenyl)hydrazono)-1-phenylbutane-1,3-dione: recent evidences from theory and experiment. Journal of Molecular Liquids, 2019(283), 242-248.

https://doi.org/10.1016/j.molliq.2019.03.073

\section{General rights}

Copyright and moral rights for the publications made accessible in the public portal are retained by the authors and/or other copyright owners and it is a condition of accessing publications that users recognise and abide by the legal requirements associated with these rights.

- Users may download and print one copy of any publication from the public portal for the purpose of private study or research.

- You may not further distribute the material or use it for any profit-making activity or commercial gain.

- You may freely distribute the URL identifying the publication in the public portal.

Take down policy

If you believe that this document breaches copyright please contact rucforsk@kb.dk providing details, and we will remove access to the work immediately and investigate your claim. 


\section{Accepted Manuscript}

Isomerization

and

aggregation

2-(2-(2-hydroxy-4-nitrophenyl)hydrazono)-1-phenylbutane-1,3-dione:

Recent evidences from theory and experiment

Silvia Hristova, Fadhil S. Kamounah, Aurelien Crochet, Poul Erik Hansen, Katharina M. Fromm, Daniela Nedeltcheva, Liudmil Antonov

PII:

S0167-7322(18)35714-3

DOI: https://doi.org/10.1016/j.molliq.2019.03.073

Reference: MOLLIQ 10614

To appear in: Journal of Molecular Liquids

Received date:

4 November 2018

Revised date:

6 March 2019

Accepted date:

14 March 2019

Please cite this article as: S. Hristova, F.S. Kamounah, A. Crochet, et al., Isomerization and aggregation of 2-(2-(2-hydroxy-4-nitrophenyl)hydrazono)-1-phenylbutane-1,3-dione: Recent evidences from theory and experiment, Journal of Molecular Liquids, https://doi.org/10.1016/j.molliq.2019.03.073

This is a PDF file of an unedited manuscript that has been accepted for publication. As a service to our customers we are providing this early version of the manuscript. The manuscript will undergo copyediting, typesetting, and review of the resulting proof before it is published in its final form. Please note that during the production process errors may be discovered which could affect the content, and all legal disclaimers that apply to the journal pertain. 
Isomerization and aggregation of 2-(2-(2-hydroxy-4-nitrophenyl)hydrazono)-1-phenylbutane1,3-dione: recent evidences from theory and experiment

Silvia Hristova ${ }^{1}$, Fadhil S. Kamounah ${ }^{2,3}$, Aurelien Crochet $^{4}$, Poul Erik Hansen ${ }^{3}$, Katharina M. Fromm ${ }^{4}$, Daniela Nedeltcheva ${ }^{1}$, Liudmil Antonov ${ }^{1 *}$

${ }^{1}$ Institute of Organic Chemistry with Centre of Phytochemistry, Bulgarian Academy of Sciences, Acad. G. Bonchev str., bldg. 9, 1113 Sofia, Bulgaria

${ }^{2}$ Department of Chemistry, University of Copenhagen, Universitetsparken 5, DK-2100 Copenhagen $\varnothing$, Denmark

${ }^{3}$ Department of Science and Environment, Roskilde University, DK-4000, Roskilde, Denmark

${ }^{4}$ Department of Chemistry, University of Fribourg, Chemin du Musée 9, CH-1700 Fribourg, Switzerland

\section{Abstract}

The title compound potentially can exist as four isomers in solution. Recently Lycka has proposed a protocol for distinguishing two of them based on ${ }^{15} \mathrm{~N} N \mathrm{NR}$. This approach has been confirmed theoretically, in the current study, and further developed into a logical scheme that allows the existence of each of the isomers to be proven in solution. The experimental data, obtained by NMR and UV-Vis spectroscopy, have shown that the studied compound exists as a mixture of two solvent stabilized isomers in diluted solutions of dimethyl sulfoxide. However, the concentration effect also plays a substantial role allowing formation of linear aggregates as the X-ray analysis and theoretical calculations show.

Keywords: rotary switch, NMR, DFT, X-ray, aggregation

\section{Introduction:}

The title compound, structure 1 in Scheme 1, has been synthesized by Mahmudov at al. [1,2] and studied by using molecular spectroscopy in relation to its potential tautomerism. The authors have stated that $\mathbf{1}$ exists as a mixture between azo and hydrazone tautomers in methanol and dimethyl sulfoxide (DMSO). Recently we have investigated the spectral behaviour of 1 in a variety of solvents, proving that the conclusions previously made for the existence of the azo tautomer are wrong [3]. The combined use of UV-Vis spectroscopy, NMR $\left({ }^{1} \mathrm{H}\right.$ and $\left.{ }^{13} \mathrm{C}\right)$ and theoretical calculations has shown that the investigated compound exists as a mixture of

\footnotetext{
${ }^{*}$ Corresponding author.
} 
isomers of the hydrazone tautomer, generally assigned as E-oriented (major form) and Zoriented (minor form) in Scheme 1. Very recently Lycka [4], using ${ }^{15} \mathrm{~N} N M R$, reached the same conclusion for $\mathbf{1}$ and $\mathbf{2}$ in DMSO and deuterochloroform.

However, the previous studies have left some questions open. On one side, according to the theoretical calculations, four isomers could exist in solution (Scheme 2). It was concluded that their stabilization depends on the solvent - structures 1 $\mathbf{E}^{\prime}$ and $1 \mathbf{Z}^{\prime}$ are presented in DMSO possibly as a result of a solute-solvent interaction. Compound 1 spontaneously deprotonates at low concentrations and aggregates at high concentrations $\left(10^{-4} \mathrm{M}\right.$ and higher) according to the UV-Vis investigations [3]. These two processes are linked and depend strongly on the solvent. Although the dimer existence was proven indirectly, its exact structure could not be established using molecular spectroscopy. Therefore, a theoretical guess was made, suggesting linear wirelike aggregates between $\mathbf{E}^{\prime}$ isomers (Scheme 3) with participation of the $\mathrm{OH}$ groups, which explains the deprotonation at low concentrations. This opens a general question about the reasons for stabilization of the $\mathbf{E}^{\prime}$ and $\mathbf{Z}^{\prime}$ isomers in which an $\mathrm{OH}$ group exists that is unengaged in intramolecular hydrogen bonding- either by formation of complexes with proton acceptor solvents or traces of water, or aggregation in all solvents. Due to the very low solubility of $\mathbf{1}$ in most of the solvents, this question is difficult to be answered purely experimentally.
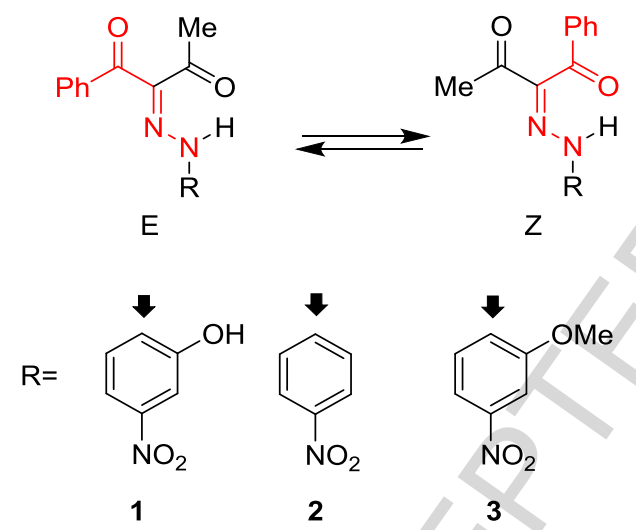

Scheme 1. Isomers of the structures under study.

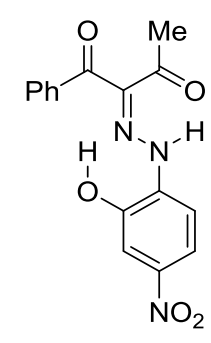

$1 E$

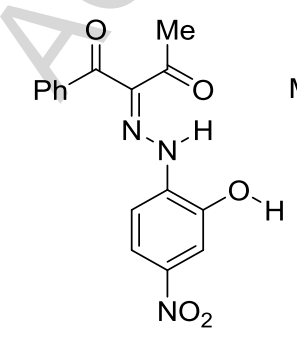

$1 E^{\prime}$

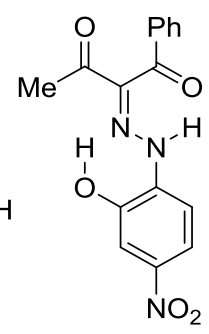

12<smiles>CC(=O)C(=NNc1ccc([N+](=O)[O-])cc1O)C(=O)c1ccccc1</smiles>

1Z'

Scheme 2. Possible isomers of the hydrazone form of 1. 


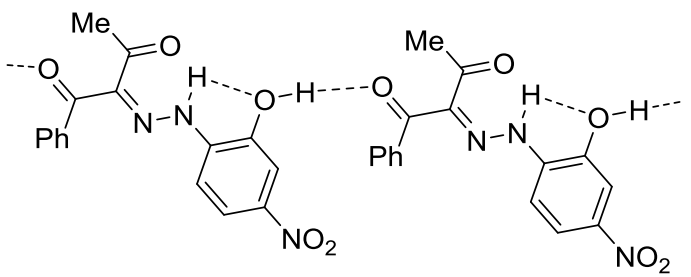

Scheme 3. Sketch of the linear aggregate of $\mathbf{1 \mathbf { E } ^ { \prime }}$.

Therefore, in the current communication, we will theoretically check the reliability of the approach proposed by Lycka [4] and will use his data to suggest a general logical scheme for distinguishing between all four isomers. A combination between theoretical and experimental data will be used to prove the effects of the concentration and solvent in the stabilization of the $\mathbf{E}^{\prime}$ and $\mathbf{Z}^{\prime}$ isomers in dimethyl sulfoxide.

\section{Experimental part:}

\section{Compounds:}

The synthesis of the compounds has been described previously [3].

\section{Spectral measurements:}

Spectral measurements were performed on Jasco V-570 UV-Vis-NIR spectrophotometer, equipped with a thermostatic cell holder (using Huber MPC-K6 thermostat with precision $1^{\circ} \mathrm{C}$ ), in spectral grade solvents at ambient temperature.

The NMR spectra were recorded at $400 \mathrm{MHz}$ for ${ }^{1} \mathrm{H}$ and at $100.6 \mathrm{MHz}$ for ${ }^{13} \mathrm{C}$ at a Bruker 400 Avance III NMR spectrometer. TMS or the solvent signal was used as reference. NOE and HMBC spectra are recorded using standard pulse programs and conditions.

\section{X-ray measurements:}

Single crystals of $\mathrm{C}_{16} \mathrm{H}_{13} \mathrm{~N}_{3} \mathrm{O}_{5}$ (1) were obtained from methanol by slow evaporation. A suitable crystal was selected and mounted on a loop with oil and measured on a STOE IPDS II diffractometer. The crystal was kept at 250(2) K during data collection. Using Olex2 [5], the structure was solved with the ShelXT structure solution program [6] using intrinsic phasing, and refined with the ShelXL refinement package [7] using least squares minimization.

Crystal Data for $\mathrm{C}_{16} \mathrm{H}_{13} \mathrm{~N}_{3} \mathrm{O}_{5}(M=327.29 \mathrm{~g} / \mathrm{mol})$ : monoclinic, space group $P 2_{1} / \mathrm{n}$ (no. 14), $a=$ $10.3609(6) \AA, b=8.7949(3) \AA, c=16.8458(10) \AA, b=93.153(5)^{\circ}, V=1532.72(14) \AA^{3}, Z=4, T=$ $250(2) \mathrm{K}, \mu\left(\mathrm{MoK}_{\alpha}\right)=0.108 \mathrm{~mm}^{-1}, D_{\text {calc }}=1.418 \mathrm{~g} / \mathrm{cm}^{3}, 19148$ reflections measured $\left(4.508^{\circ} \leq 2 \Theta \leq\right.$ $\left.50.218^{\circ}\right), 2733$ unique $\left(R_{\text {int }}=0.0358, R_{\text {sigma }}=0.0166\right)$, which were used in all calculations. The final $R_{1}$ was $0.0286(\mathrm{I}>2 \sigma(\mathrm{I}))$, and $w R_{2}$ was 0.0786 (all data). Crystallographic data have been deposited with the Cambridge Crystallographic Data Centre (CCDC-1858058 (1)). Copies may be 
obtained free of charge on application to the Director, CCDC, 12 Union Road, Cambridge CB2 1EZ, UK (e-mail: deposit@chemcrys.cam.ac.uk).

Compound 1 crystallizes in the monoclinic space group $P 2_{1} /$ n (No. 14) with one molecule per asymmetric unit. The phenyl moiety is twisted by $61^{\circ}$ with respect to the mean plane formed by the rest of the atoms of $\mathbf{1}$, probably due to steric reasons. An intramolecular $\mathrm{H}$-bond is found between $\mathrm{O} 4$ and $\mathrm{N} 1-\mathrm{H} 1$ with a distance of $1.888 \AA$ and an angle of $130.7^{\circ}$. Intermolecular $\mathrm{H}$ bonds are found between $\mathrm{O} 1-\mathrm{H} 1 \mathrm{~A}$ and $\mathrm{O} 5$ of a neighbor molecule with $1.884 \AA$ and an angle of almost $176^{\circ}$. Molecules pack pairwise in a head-to-tail manner with short distances involving $\pi-\pi$ contacts between e.g. N2 and C6 (3.398 $)$ ), C4 and C15 (3.441 $)$ and C4 and C7 (3.541 $)$ ), Figure 1. With respect to one such pair, the next pair is parallel, but offset by ca. $4.3 \AA$, still involving $\pi-\pi$ stacking between the carbonyl groups $\mathrm{C} 15-04$ and its symmetry equivalent, at distances of $3.225 \AA$, as well as a short N1-C16 contact of $3.354 \AA$. The tilted phenyl ring is involved in an intermolecular $\mathrm{H}$-bond between $\mathrm{H} 10$ and $\mathrm{O} 4$ with a distance of 2.681 and an C10-H10-O4 angle of $162^{\circ}$.

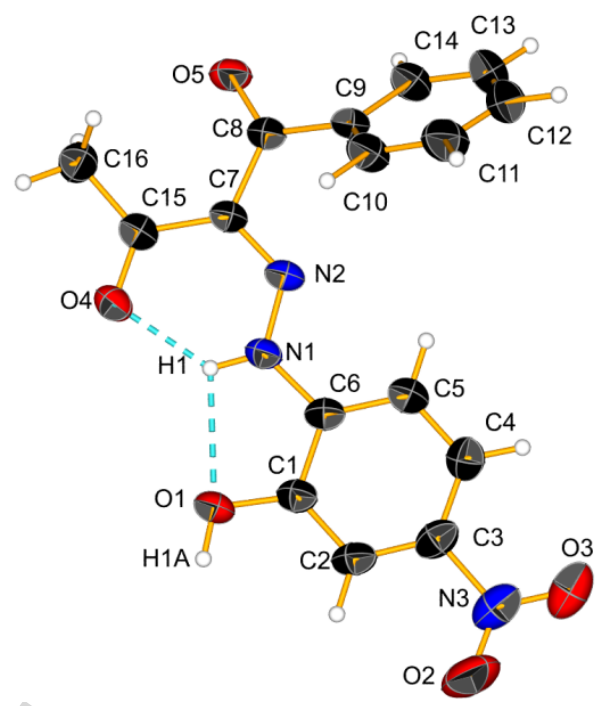




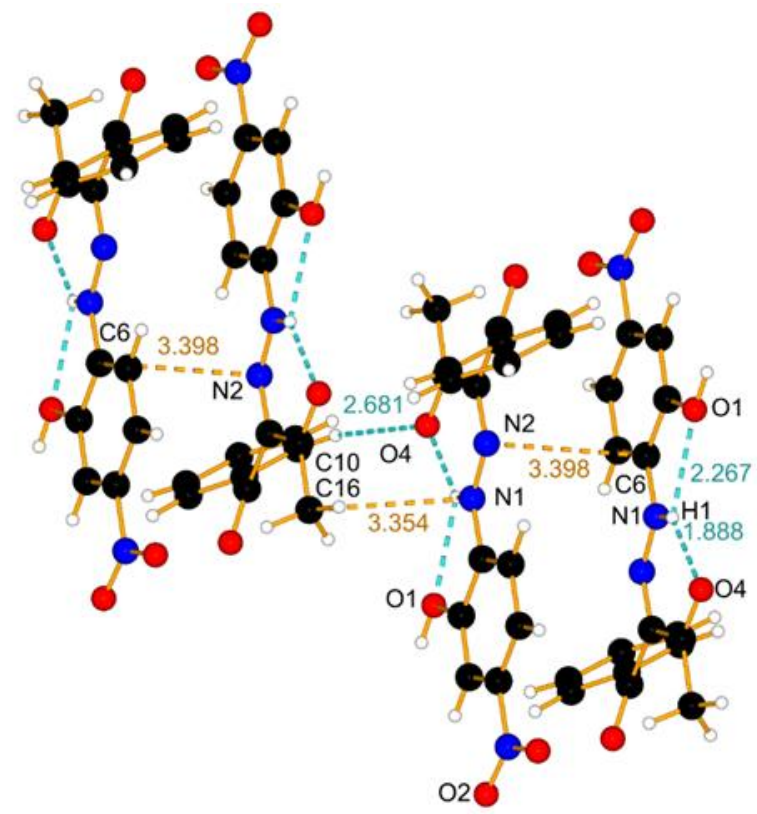

Figure 1. Above: Ortep representation of 1 , ellipsoids are drawn with $50 \%$ of probability, $\mathrm{H}$ bonds are draw as blue dash lines; Below: Stacking of 1, $\mathrm{H}$-bonds are drawn as dash blue lines and short contact as dash orange lines; for clarity, only the shortest short contacts are represented.

\section{Quantum-chemical calculations:}

Quantum-chemical calculations were performed by using the Gaussian 09 program suite [8]. If not explicitly described, the M06-2X functional $[9,10]$ was used with the TZVP basis set [11]. This fitted hybrid meta-GGA functional with $54 \%$ HF exchange is especially developed to describe main-group thermochemistry and the non-covalent interactions, showing very good results in the prediction of the position of the tautomeric equilibrium in azo naphthols possessing intramolecular hydrogen bonds, [12] and in the description of the proton transfer reactions in naphthols $[13,14]$. All structures were optimized without restrictions, using tight optimization criteria and ultrafine grid in the computation of two-electron integrals and their derivatives, and the true minima were verified by performing frequency calculations in the corresponding environment. Solvent effects are described by using the Polarizable Continuum Model (the integral equation formalism variant, IEFPCM, as implemented in Gaussian 09) [15]. The absorption spectra of the compounds were predicted using the TD-DFT formalism. TD-DFT calculations were carried out at the same functional and basis set, which is in accordance with conclusions about the effect of the basis set size and the reliability of the spectral predictions [16-18].

The NMR chemical shieldings of selected tautomeric forms of the studied compounds were calculated using the GIAO approximation [19] at the B3LYP/6-311+G(2d,p) level of theory. This level of theory was recommended in the pioneering work by Cheeseman et al. [20], focused on 
the comparison of different models for calculating nuclear magnetic resonance shielding tensors and shows very good results in predicting the NMR spectra of azo-hydrazone tautomerism [21]. The calculated absolute shieldings were transformed to chemical shifts using the reference compound tetramethylsilane, $\mathrm{Si}\left(\mathrm{CH}_{3}\right)_{4}$, for hydrogen, carbon and nitromethane, $\mathrm{CH}_{3} \mathrm{NO}_{2}$, for nitrogen atoms: $\delta=\delta_{\text {calc }}($ ref $)-\delta_{\text {calc }}$. Both $\delta_{\text {calc }}($ ref $)$ and $\delta_{\text {calc }}$ were evaluated at the same computational level. For the ${ }^{1} \mathrm{H}$ chemical shifts the experimental and calculated shifts of compounds 1 and $\mathbf{3}$ in DMSO were plotted again each other to gives a linear equation $\delta\left({ }^{1} \mathrm{H}\right)_{\text {experimental }}=-0.956 \times \delta\left({ }^{1} \mathrm{H}\right)_{\text {calculated }}+30.516\left(\mathrm{R}^{2}=0.995\right.$, Supplementary information, Tables S1 and S2, Figure S1).

\section{Results and discussion:}

As seen from Table 1, where the theoretical results are summarized, in all solvents the $\mathbf{E}$ form should be more stable, followed by the $\mathbf{E}^{\prime}$ isomer, practically in the whole range (as dielectric constant) of used solvents when implicit solvation is applied. According to the calculations measurable amounts of $\mathbf{E}$ and $\mathbf{E}^{\prime}$ could be presented in solution and $\mathbf{Z}^{\prime}$ could be seen in polar solvents in amounts to less than a few percent. The availability of the $\mathrm{OH}$ group, not involved in intramolecular hydrogen bonding, in $\mathbf{E}^{\prime}$ and $\mathbf{Z}^{\prime}$, allows their substantial stabilization when specific interaction with DMSO or water molecules is considered by adding explicit solvent molecules. The same type of stabilization can be achieved when homodimers (interaction between two molecules following the pattern in Scheme 3) are formed. It is difficult to determine which of these two processes is stronger, because the stabilization energies are almost the same. The stabilization energies ${ }^{\dagger}$ of the DMSO complexes of $\mathbf{E}^{\prime}$ and $\mathbf{Z}^{\prime}$ are 13 and $12.9 \mathrm{kcal} / \mathrm{mol}$ respectively, while the stabilization through wire-like dimer $^{\ddagger}$ is 12.2 and 11.4 $\mathrm{kcal} / \mathrm{mol}$. Correspondingly, the closed forms $\mathbf{E}$ and $\mathbf{Z}$, where neither strong solvent complexes nor stable dimers could be possible, are destabilized. Here specific solvation with proton donor solvents, involving the free $\mathrm{C}=0$ group could be expected, but the same could exists in $\mathbf{E}^{\prime}$ and $\mathbf{Z}^{\prime}$ as well, which nulls the effect. In acetonitrile no strong solvent complexes could be expected, while the aggregation cannot be fully excluded, taking into account that the stabilization energies are almost the same as in DMSO.

Taking into account that all four isomers are almost identical from the viewpoint of UV-Vis spectroscopy, their identification in DMSO was made by careful analysis of the NMR spectra of $\mathbf{1}$ by using $\mathbf{3}$ as a reference compound [3]. It was shown on basis of ${ }^{1} \mathrm{H}$ and ${ }^{13} \mathrm{C}$ spectra that $\mathbf{E}^{\prime}$ and $\mathbf{Z}^{\prime}$ forms are presented in solution as major and minor component, respectively, which matches the theoretical predictions very well. The recent study of Lycka has brought additional, ${ }^{15} \mathrm{~N}$ NMR based, evidences for stronger stabilization of the E-oriented COMe group [4]. His conclusions are based on using ${ }^{2} \mathrm{~J}\left({ }^{15} \mathrm{~N}_{\beta},{ }^{13} \mathrm{C}\right)$ constants of 1 in DMSO- $\mathrm{d}_{6}$. According to Cheatham

\footnotetext{
${ }^{\dagger}$ Defined as $\Delta \mathrm{E}=\left(\mathrm{E}_{\text {isomer }}+\mathrm{E}_{\mathrm{DMSO}}\right)-\mathrm{E}_{\text {complex }}$. Positive value indicates that the complex is favored.

* Defined as $\Delta \mathrm{E}=2 . \mathrm{E}_{\text {monomer }}-\mathrm{E}_{\text {dimer }}$. Positive value indicates that the dimer is favored.
} 
et al. [22] the differences in these constants could be large enough and can easily denote which carbonyl carbon is closer to the electron lone pair of $N_{\beta}$ nitrogen (see Scheme 4 for the numbering). The measured ${ }^{2} \mathrm{~J}$ values (in $\mathrm{Hz}$ ) for the major isomer are correspondingly $<1$ for $\mathrm{C}-2$ and 11.9 for $\mathrm{C}-4$, showing that the Ph-linked carbonyl carbon is closer to the $\mathrm{N}_{\beta}$ nitrogen lone pair. The opposite is proven for the minor component, which was assigned as Z-oriented. These trends have been reproduced theoretically as summarized in Table 2. The theoretically predicted ${ }^{2} \mathrm{~J}\left({ }^{15} \mathrm{~N}_{\beta},{ }^{13} \mathrm{C}-4\right)$ constants are huge in the case of $\mathbf{E}\left(\mathbf{E}^{\prime}\right)$ forms and negligible for $\mathbf{Z}\left(\mathbf{Z}^{\prime}\right)$ ones. The exactly opposite is true for ${ }^{2} \mathrm{~J}\left({ }^{15} \mathrm{~N}_{\beta},{ }^{13} \mathrm{C}-2\right)$. The obtained trends and values confirm reasonably well the experimental data (Table 2). Although it is known that ${ }^{13} \mathrm{C}-{ }^{15} \mathrm{~N}$ couplings over two or three bonds are generally small, we have calculated ${ }^{2} \mathrm{~J}\left({ }^{15} \mathrm{~N}_{\alpha},{ }^{13} \mathrm{C}\right)$ couplings. The calculated results show for $C^{-} 2^{\prime}$ in respect of $N_{\alpha}$ values of $1.0 \mathrm{~Hz}$ corresponding to $\mathrm{E}^{\prime} / \mathbf{Z}^{\prime}$, while values for $2.9 \mathrm{~Hz}$ of $C^{-} 6^{\prime}$ are calculated for the $E / Z$ isomers. In the paper of Lycka the value ${ }^{2} \mathrm{~J}\left({ }^{15} \mathrm{~N}_{\alpha}{ }^{13} \mathrm{C}-2^{\prime}\right)$ was measured as 1.6 for the major isomer and 1.5 for the minor one, and no value for ${ }^{2} \mathrm{~J}\left({ }^{15} \mathrm{~N}_{\alpha},{ }^{13} \mathrm{C}-6{ }^{\prime}\right)$ is shown [4]. Consequently the combined use of ${ }^{2} \mathrm{~J}\left({ }^{15} \mathrm{~N}_{\alpha},{ }^{13} \mathrm{C}\right)$ and ${ }^{2} \mathrm{~J}\left({ }^{15} \mathrm{~N}_{\beta},{ }^{13} \mathrm{C}\right)$ confirms the availability of $1 \mathrm{E}^{\prime}$ as a major component and $\mathbf{1 Z}$ ', as a minor ones, in solution.

In the general context of the study of isomerization of similar rotary switches, the use of the combination of these two ${ }^{2} \mathrm{~J}$ constants gives a good opportunity to distinguish between $\mathrm{E}$ and $\mathrm{Z}$ and their corresponding ' analogues: ${ }^{2} \mathrm{~J}\left({ }^{15} \mathrm{~N}_{\alpha},{ }^{13} \mathrm{C}-2\right.$ ') is defined by the $\mathrm{N}_{\alpha}-\mathrm{C}-1$ ' rotation, while ${ }^{2} \mathrm{~J}\left({ }^{15} \mathrm{~N}_{\beta},{ }^{13} \mathrm{C}-2\right)$ is a function of the $\mathrm{N}_{\beta}-\mathrm{C}-1$ bond rotation. As a result each of the four isomers, shown in Scheme 2, can be presented as a unique logical combination (small/large) of the ${ }^{2} \mathrm{~J}$ constants and the assignment can be easily done based on the experimental data (Table 2).<smiles>CC(=O)[C@H](NNc1ccc([N+](=O)[O-])cc1O)C(=O)c1ccccc1</smiles>

Scheme 4. Numbering of carbonyl and nitrogen atoms in $\mathbf{1}$.

Table 1. Relative energies (M06-2X/TZVP) of the isomers of $1^{*}$ in various solvents in $\mathrm{kcal} / \mathrm{mol}$ units.

\begin{tabular}{|c|c|c|c|c|c|}
\hline Specie & Isomer & $\begin{array}{c}\text { Solvent } \\
\text { (PCM model) }\end{array}$ & $\Delta \mathrm{E}$ & $\Delta \mathrm{E}+\mathrm{ZPE}$ & $\Delta \mathrm{G}$ \\
\hline \multirow{3}{*}{ Monomer } & $\mathbf{E}$ & \multirow{3}{*}{ Chloroform } & 0.00 & 0.00 & 0.00 \\
\hline & $\mathbf{Z}$ & & $\begin{array}{c}2.44(1.62) \\
1.83^{* *}\end{array}$ & $2.41(1.38)$ & $2.07(1.03)$ \\
\hline & $E^{\prime}$ & & 0.94 & 0.88 & 0.29 \\
\hline
\end{tabular}




\begin{tabular}{|c|c|c|c|c|c|}
\hline & & & $1.26^{* *}$ & & \\
\hline & $Z^{\prime}$ & & $\begin{array}{c}2.54 \\
2.72 * *\end{array}$ & 2.16 & 1.19 \\
\hline & E & \multirow{4}{*}{ Acetonitrile } & 0.00 & 0.00 & 0.00 \\
\hline & $\bar{Z}$ & & $\begin{array}{c}2.07(1.13) \\
1.48^{* *}\end{array}$ & $2.07(0.86)$ & $1.83(0.39)$ \\
\hline & $\mathrm{E}^{\prime}$ & & $\begin{array}{c}0.79 \\
1.07^{* *}\end{array}$ & 0.84 & 0.54 \\
\hline & $\mathrm{Z}^{\prime}$ & & $\begin{array}{c}1.93 \\
2.14^{* *}\end{array}$ & 1.48 & 0.71 \\
\hline & $\mathbf{E}$ & \multirow{10}{*}{ DMSO } & 0.00 & 0.00 & 0.00 \\
\hline & $\mathbf{Z}$ & & $\begin{array}{c}2.06(1.11) \\
1.46^{* *}\end{array}$ & $2.05(0.83)$ & $1.83(0.35)$ \\
\hline & $E^{\prime}$ & & $\begin{array}{c}0.78 \\
1.07^{* *}\end{array}$ & 0.84 & 0.57 \\
\hline & $\mathbf{Z}^{\prime}$ & & $\begin{array}{c}1.90 \\
2.12^{* *}\end{array}$ & 1.53 & 0.71 \\
\hline \multirow{4}{*}{$\begin{array}{l}\text { monomer- } \\
\text { DMSO } \\
\text { complex**** }\end{array}$} & $E$ & & $\begin{array}{c}4.65 \\
7.96^{* *}\end{array}$ & 4.85 & 5.59 \\
\hline & $\mathbf{Z}$ & & $\begin{array}{c}2.30 \\
7.85^{* *}\end{array}$ & 1.97 & 2.82 \\
\hline & $E^{\prime}$ & & 0.00 & 0.00 & 0.00 \\
\hline & $\mathrm{Z}^{\prime}$ & & $\begin{array}{c}1.15 \\
0.89 * *\end{array}$ & 0.89 & 0.49 \\
\hline \multirow[b]{2}{*}{ Dimer } & $E^{\prime}-E^{\prime}$ & & 0.00 & 0.00 & $0.00 * * *$ \\
\hline & $Z^{\prime}-Z^{\prime}$ & & $\begin{array}{c}1.43 \\
1.75^{* *}\end{array}$ & 0.96 & $0.05^{* * *}$ \\
\hline
\end{tabular}

* relative energies in the case of $\mathbf{2}$ are given in brackets; ${ }^{* *}$ relative energies in the case of $\mathbf{1}$ using B3LYP/6-311+G(2d,p)//M06-2X/TZVP; *** less reliable due to very low first positive frequency; ${ }^{* * *}$ the corresponding water complexes in water environment have the following relative energies (following the same order from $\mathbf{E}$ to $\mathbf{Z}^{\prime}$ ): $3.25,3.59,0.0,1.07 \mathrm{kcal} / \mathrm{mol}$, the predicted complexes are shown in Figure S2.

Table 2. Predicted (B3LYP/6-311+G(2d,p)//M06-2X/TZVP) and experimental ${ }^{15} \mathrm{~N} \quad \mathrm{NMR}$ parameters of selected atoms of 1 in DMSO.

\begin{tabular}{|c|c|c|c|c|c|c|c|c|c|}
\hline \multirow[t]{2}{*}{ Structure } & \multicolumn{3}{|c|}{$\delta\left({ }^{1} \mathrm{H}\right), \mathrm{ppm}$} & \multicolumn{2}{|c|}{$\delta\left({ }^{15} \mathrm{~N}\right), \mathrm{ppm}$} & \multicolumn{2}{|c|}{$\begin{array}{c}{ }^{2} \mathrm{~J}\left({ }^{15} \mathrm{~N}_{\beta}{ }^{13} \mathrm{C}\right) \\
\mathrm{Hz}\end{array}$} & \multicolumn{2}{|c|}{$\begin{array}{c}{ }^{2} \mathrm{~J}\left({ }^{15} \mathrm{~N}_{\alpha}{ }^{13} \mathrm{C}\right) \\
\mathrm{Hz}\end{array}$} \\
\hline & $\mathrm{OH}$ & $\mathrm{NH}$ & $H-6^{\prime}$ & $\mathrm{N}_{\alpha}$ & $\mathrm{N}_{\beta}$ & $\mathrm{C}-2$ & C-4 & $C-2^{\prime}$ & $C-6^{\prime}$ \\
\hline$E$ & 9.15 & 14.54 & 7.34 & -208.7 & -35.9 & -0.4 & 8.2 & -0.3 & 2.9 \\
\hline Z & 10.12 & 12.96 & 7.35 & -217.4 & -46.1 & 8.3 & -0.6 & -0.2 & 2.8 \\
\hline$E^{\prime}$ & 5.28 & 14.35 & 7.74 & -219.3 & -16.2 & -0.1 & 9.0 & 1.0 & -0.1 \\
\hline$Z^{\prime}$ & 5.24 & 12.73 & 8.34 & -227.6 & -26.1 & 9.3 & -0.4 & 1.0 & -0.1 \\
\hline E-DMSO & 9.43 & 14.69 & 8.83 & -200.7 & -39.0 & -0.3 & 8.5 & -0.3 & 2.8 \\
\hline
\end{tabular}




\begin{tabular}{|c|c|c|c|c|c|c|c|c|c|}
\hline complex & & & & & & & & & \\
\hline $\begin{array}{l}\text { Z-DMSO } \\
\text { complex }\end{array}$ & 10.22 & 13.30 & 7.78 & -215.2 & -54.9 & 8.1 & -1.2 & -0.3 & 2.9 \\
\hline $\begin{array}{l}\text { E'-DMSO } \\
\text { complex }\end{array}$ & $\begin{array}{r}13.71 \\
(10.94)^{*}\end{array}$ & $\begin{array}{r}14.35 \\
(14.31)^{*}\end{array}$ & $\begin{array}{r}7.63 \\
(7.65)^{*} \\
\end{array}$ & -215.0 & -13.7 & -0.1 & 9.0 & 1.1 & -0.1 \\
\hline $\begin{array}{l}\mathrm{Z}^{\prime} \text {-DMSO } \\
\text { complex }\end{array}$ & $\begin{array}{r}13.71 \\
(10.92)^{*} \\
\end{array}$ & $\begin{array}{r}12.95 \\
(12.84)^{*}\end{array}$ & $\begin{array}{r}8.24 \\
(8.27)^{*} \\
\end{array}$ & -223.0 & -23.4 & 9.3 & -0.4 & 1.1 & -0.1 \\
\hline $\begin{array}{c}\mathbf{E}^{\prime}-\mathbf{E}^{\prime} \\
\text { aggregate }\end{array}$ & 10.34 & 14.49 & 7.49 & -216.5 & -14.6 & -0.2 & 10.0 & 1.1 & -0.1 \\
\hline $\begin{array}{c}\mathbf{Z}^{\prime}-\mathbf{Z}^{\prime} \\
\text { aggregate }\end{array}$ & 8.95 & 12.82 & 8.16 & -225.0 & -24.3 & 9.7 & -0.4 & 1.0 & -0.1 \\
\hline $\begin{array}{l}\text { major form } \\
\left(E^{\prime}\right)^{* *, * * *}\end{array}$ & 11.52 & 14.14 & 7.20 & $\begin{array}{r}-220.9 \\
* * *\end{array}$ & $\begin{array}{r}-21.3 \\
* * * \\
\end{array}$ & $\begin{array}{c}<1 \\
* * * \\
\end{array}$ & $\begin{array}{l}11.9 \\
* * *\end{array}$ & $\begin{array}{l}1.6 \\
* * *\end{array}$ & \\
\hline $\begin{array}{l}\text { minor form } \\
\left(\mathrm{Z}^{\prime}\right)^{* * * * * *}\end{array}$ & 11.34 & 11.70 & 7.75 & $\begin{array}{r}-229.7 \\
* * * \\
\end{array}$ & $\begin{array}{r}-29.8 \\
* * * \\
\end{array}$ & $\begin{array}{l}12.5 \\
* * * \\
\end{array}$ & $\begin{array}{c}<1 \\
* * *\end{array}$ & $\begin{array}{r}1.5 \\
* * * \\
\end{array}$ & \\
\hline
\end{tabular}

* water complex in DMSO (see Figure S2);** experimentally measured [3], also in Figure S1;

** taken from [4], relative error $\pm 0.3 \mathrm{~Hz}$ for ${ }^{2} \mathrm{~J}$ constants;

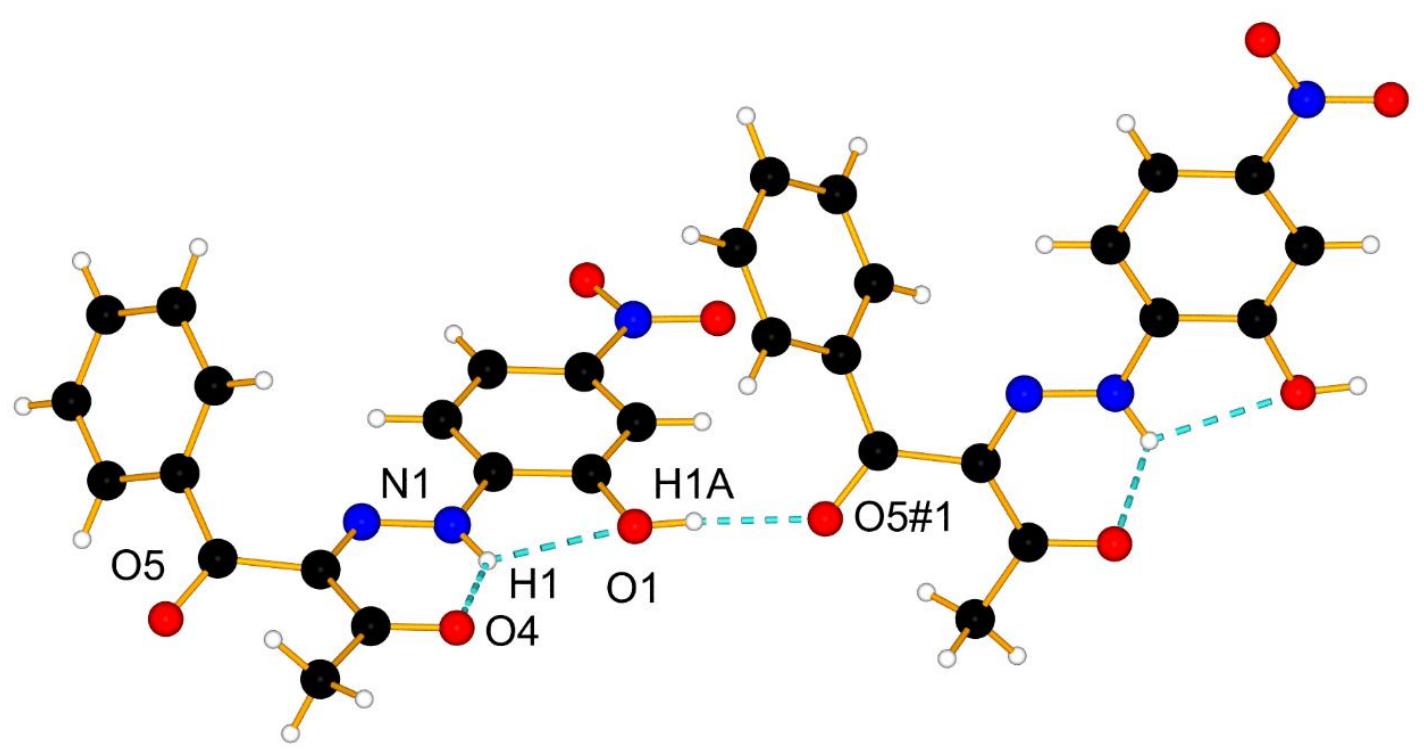




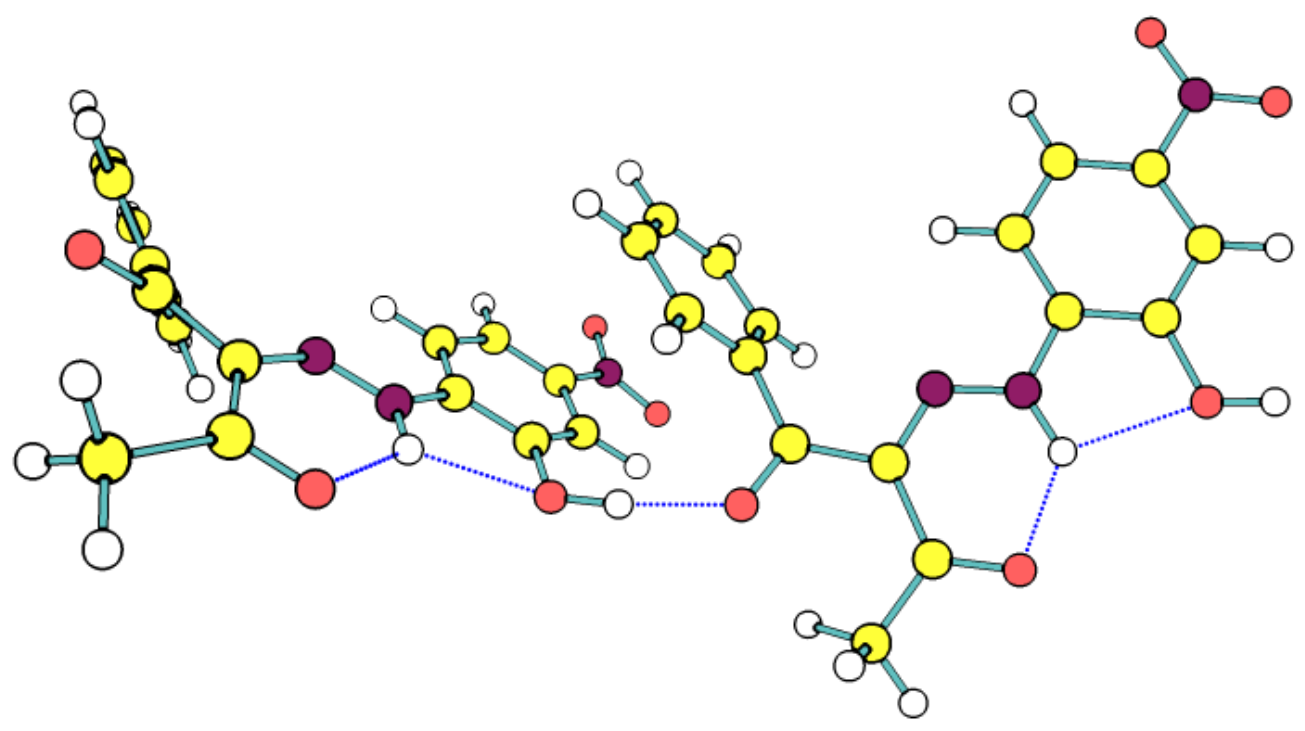

Figure 2. H-bonds motifs of 1 (upper), H-bonds are draw as blue dash lines, Symm. op.: -1/2+x, $3 / 2-y,-1 / 2+z$; Theoretically predicted dimer of $1 \mathbf{E}^{\prime}$ (down).

The crystal structure of $\mathbf{1}$ is shown in Figure 2. Two conclusions can be drawn from it: the studied compound exists as $\mathbf{E}^{\prime}$ isomer in the solid state, which confirms previously made conclusions for its dominance in proton acceptor solvents [3] or in solvents with mixed nature like methanol or water (see relative stability in water as a guideline, Table 1); as predicted by the theoretical calculations, $\mathbf{1} \mathbf{E}^{\prime}$ is stabilized by formation of linear aggregates (Figure S3) and as can be seen from Figure 1 there is a very good match between theory and experiment, again taking into account the fact that crystals were grown in methanol. This particular structure of the aggregate excludes effective overlapping of the electronic density of the monomers and, consequently, no substantial spectral changes in accordance with the exciton theory [13,23-25] could be observed in the absorption spectra. The theoretically predicted absorbance in both monomer and dimer, shown in Figure 1, is located in the range $352-365 \mathrm{~nm}$. Most probably the experimental spectra of both species are also almost identical and strongly overlaps, which could not bring UV-Vis spectral evidences for the self-association. The evidences are indirect: in the experimentally measured UV-Vis spectra [3] the observed changes are related only to the process of deprotonation in proton acceptor solvents at low concentrations $\left(10^{-5} \mathrm{M}\right.$ and lower) as a result of the aggregates' destruction according to the general equilibrium scheme:

Aggregates $\Leftrightarrow$ Monomers $\Leftrightarrow$ Anions

The assumed scheme brings up the question of what actually happens in proton acceptor solvents (like DMSO and DMF) at the concentration range used in the NMR measurements. As was proven, the deprotonation is a result of the formation of solute-solvent (monomer-solvent) complexes at low concentrations. Following the scheme, a rise of the concentration should thus 
reduce the monomers in favor of the aggregates, which brings a concern about the existence of the solute-solvent complexes as a whole at the NMR concentrations.

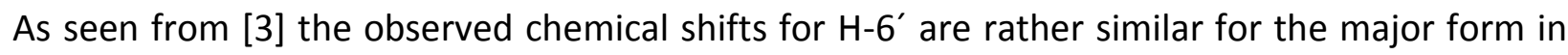
all three solvents suggesting the same molecular environment (Table 2). Furthermore, the predicted chemical shifts are almost the same for $\mathbf{E}$ and $\mathbf{Z}$, while two different values were measured for the major and minor forms and different values are predicted for $\mathbf{E}^{\prime}$ and $\mathbf{Z}^{\prime}$. The same pattern, based on structural similarities, is obvious in the predicted values for the solutesolvent complexes and the aggregates. As seen in the case of DMSO it is less obvious to distinguish between $\mathbf{E}^{\prime}$ and the $\mathbf{E}^{\prime}-\mathbf{E}^{\prime}$ aggregate based on $\mathrm{NH}$ chemical shifts.

Looking at the X-ray structure (Figure 2), the $\mathrm{H}-3^{\prime}$ to $\mathrm{H}-2^{\prime \prime}$ or $\mathrm{H}-6$ " (from the neighbor molecule in the aggregate) distances are 3.49 and $3.67 \AA$. In the calculated dimers, they are similar with 3.4 and $3.8 \AA$. These distances should allow observation of NOESY cross peaks if the complex is also present in solution. The NOESY spectrum, presented in Figure 3, a cross-peak is seen between $\mathrm{OH}$ at 11.52 to $\mathrm{H}-3^{\prime}$ at $7.72 \mathrm{ppm}$. In the previous report a cross peak with water was seen to $\mathrm{H}^{-3}$ ' and it was suggested that the hydrogen bond partner was DMSO (see Supplementary material, Figure S5). The observation of cross peaks from $\mathrm{H}_{2} \mathrm{O}$ to $\mathrm{H}-3^{\prime}$ suggests a complex with a water molecule. However, the calculations suggest that the DMSO molecule is involved as shown in Figure 4. Actually the formation of this kind of associate in presence of water explains very well why the deprotonation is suppressed in presence of water as it seen experimentally [3]. The deprotonation needs free monomers to interact directly with DMSO, which deprotonates them, while the water molecules stabilize the aggregates. In dry DMSO as, shown in Figure $\mathrm{S} 6$ the compound is substantially deprotonated. 


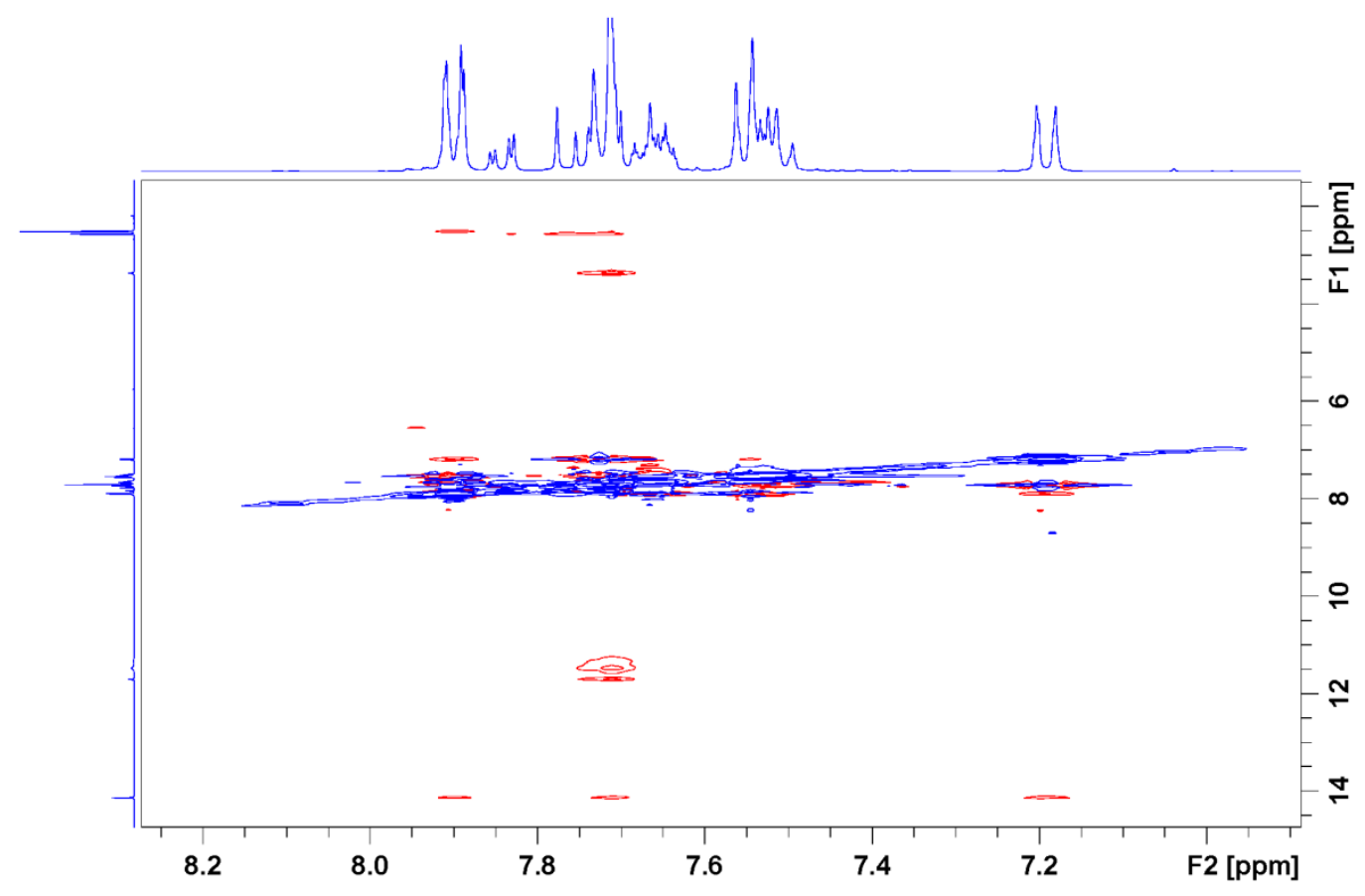

Figure 3. Part of the NOESY spectrum of 1 in DMSO- $d_{6}$ (the full spectrum is shown in Figure S4).

The calculated structure as shown in Figure 4 has reasonable distances between $\mathrm{H}-3$ 'and $\mathrm{H}-\mathrm{2}^{\prime \prime}$, $\mathrm{H}-6$ " to enable the observation of a NOE cross peak and the $\mathrm{OH}$ group is in the vicinity of $\mathrm{H}$ $3^{\prime}$ and is also hydrogen bonded indirectly to DMSO. The complex is as seen asymmetric and requires motion to give a single set of NMR resonances. The observed chemical shift for the $\mathrm{OH}$ proton should near the predicted value for the water complex, which is observed in Table 2.

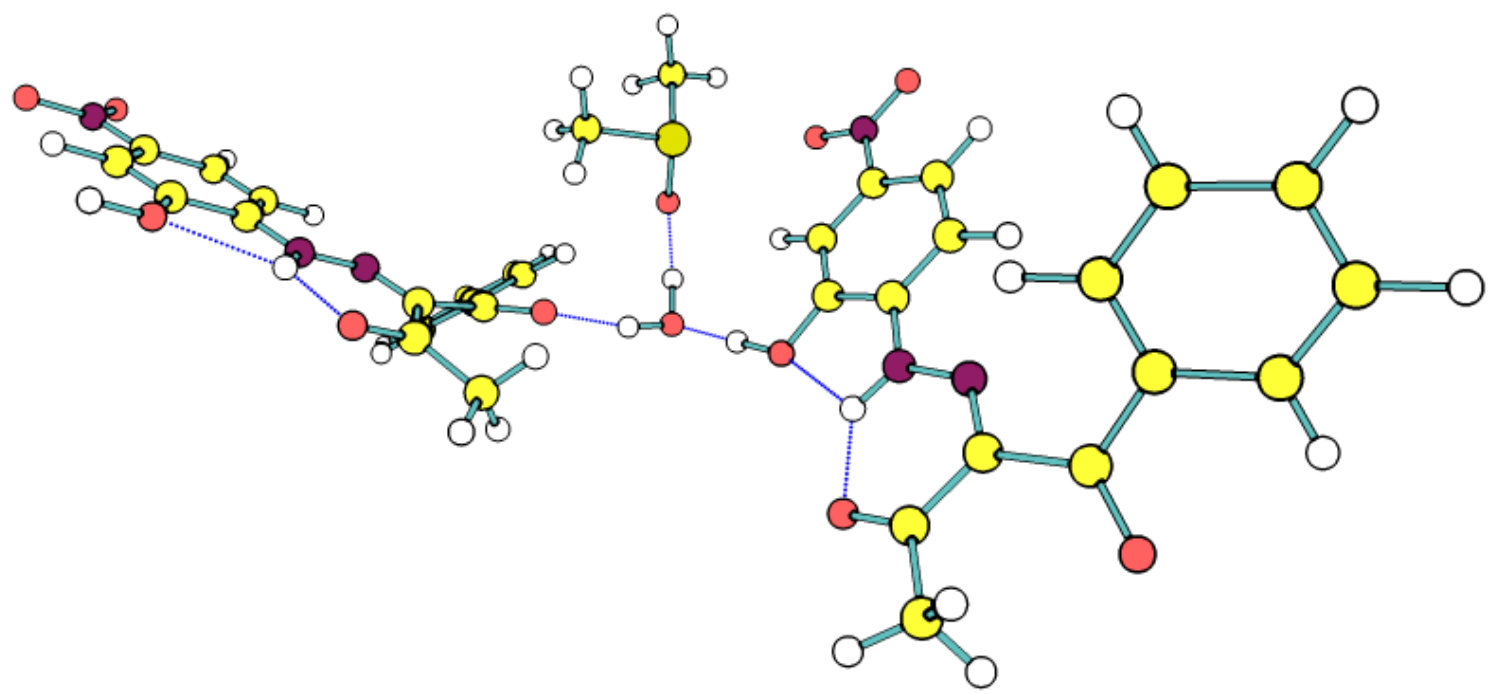


Figure 4. E'-E' complex involving water molecule as a linker.

\section{Conclusions}

Based on the experimental data published by Lycka we have proven that it is possible to distinguish between the isomers of 1 using the ${ }^{2} \mathrm{~J}$ constants in the ${ }^{15} \mathrm{~N} \mathrm{NMR}$ spectra. This approach confirms that the major form in solution of $\mathbf{1}$ and $\mathbf{3}$ is $\mathbf{E}^{\prime}$, which in the case of $\mathbf{1}$ is stabilized by forming linear aggregate. In DMSO, in presence of water, an associate involving both water and DMSO is observed, which explains experimentally observed effect of water addition. The crystallographic data confirm perfectly the theoretically predicted structure of the E' aggregates.

Acknowledgements:

The financial support by the project DFNP-17-66/26.07.2017 for support of young scientists is gratefully acknowledged. 
[1] K.T. Mahmudov, R.A. Rahimov, M.B. Babanly, P.Q. Hasanov, F.G. Pashaev, A.G. Gasanov, M.N. Kopylovich, A.J.L. Pombeiro, Tautomery and acid-base properties of some azoderivatives of benzoylacetone, Journal of Molecular Liquids. 162 (2011) 84-88. doi:10.1016/j.molliq.2011.06.005.

[2] W. Kuznik, M.N. Kopylovich, G.I. Amanullayeva, A.J.L. Pombeiro, A.H. Reshak, K.T. Mahmudov, I.V. Kityk, Role of tautomerism and solvatochromism in UV-VIS spectra of arylhydrazones of $\beta$-diketones, Journal of Molecular Liquids. 171 (2012) 11-15. doi:10.1016/j.molliq.2012.03.023.

[3] S. Hristova, F.S. Kamounah, N. Molla, P.E. Hansen, D. Nedeltcheva, L. Antonov, The possible tautomerism of the potential rotary switch 2-(2-(2-Hydroxy-4nitrophenyl)hydrazono)-1-phenylbutane-1,3-dione, Dyes and Pigments. 144 (2017) 249261. doi:10.1016/j.dyepig.2017.05.021.

[4] A. Lyčka, 15 N NMR study of ( E )- and ( Z )-2-(2-(2-hydroxy-4-nitrophenyl)hydrazono)-1phenylbutane-1,3-diones. A suitable method for analysis of hydrazone isomers, Dyes and Pigments. 150 (2018) 181-184. doi:10.1016/j.dyepig.2017.10.023.

[5] O.V. Dolomanov, L.J. Bourhis, R.J. Gildea, J.A.K. Howard, H. Puschmann, OLEX2 : a complete structure solution, refinement and analysis program, Journal of Applied Crystallography. 42 (2009) 339-341. doi:10.1107/S0021889808042726.

[6] G.M. Sheldrick, SHELXT - Integrated space-group and crystal-structure determination, Acta Crystallographica Section A Foundations and Advances. 71 (2015) 3-8. doi:10.1107/S2053273314026370.

[7] G.M. Sheldrick, Crystal structure refinement with SHELXL, Acta Crystallographica Section C Structural Chemistry. 71 (2015) 3-8. doi:10.1107/S2053229614024218.

[8] M.J. Frisch, G.W. Trucks, H.B. Schlegel, G.E. Scuseria, M.A. Robb, J.R. Cheeseman, G. Scalmani, V. Barone, B. Mennucci, G.A. Petersson, H. Nakatsuji, M. Caricato, X. Li, H.P. Hratchian, A.F. Izmaylov, J. Bloino, G. Zheng, J.L. Sonnenberg, M. Hada, M. Ehara, K. Toyota, R. Fukuda, J. Hasegawa, M. Ishida, T. Nakajima, Y. Honda, O. Kitao, H. Nakai, T. Vreven, J.A. Montgomery Jr., J.E. Peralta, F. Ogliaro, M.J. Bearpark, J. Heyd, E.N. Brothers, K.N. Kudin, V.N. Staroverov, R. Kobayashi, J. Normand, K. Raghavachari, A.P. Rendell, J.C. Burant, S.S. Iyengar, J. Tomasi, M. Cossi, N. Rega, N.J. Millam, M. Klene, J.E. Knox, J.B. Cross, V. Bakken, C. Adamo, J. Jaramillo, R. Gomperts, R.E. Stratmann, O. Yazyev, A.J. Austin, R. Cammi, C. Pomelli, J.W. Ochterski, R.L. Martin, K. Morokuma, V.G. Zakrzewski, G.A. Voth, P. Salvador, J.J. Dannenberg, S. Dapprich, A.D. Daniels, Ã. Farkas, J.B. Foresman, J.V. Ortiz, J. Cioslowski, D.J. Fox, Gaussian 09 Revision D.01, Gaussian, Inc., Wallingford, CT, USA, 2013.

[9] Y. Zhao, D.G. Truhlar, Density Functionals with Broad Applicability in Chemistry, Accounts of Chemical Research. 41 (2008) 157-167. doi:10.1021/ar700111a.

[10] Y. Zhao, D.G. Truhlar, The M06 suite of density functionals for main group thermochemistry, thermochemical kinetics, noncovalent interactions, excited states, and transition elements: two new functionals and systematic testing of four M06-class functionals and 12 other functionals, Theoretical Chemistry Accounts. 120 (2008) 215-241. doi:10.1007/s00214-007-0310-x.

[11] F. Weigend, R. Ahlrichs, Balanced basis sets of split valence, triple zeta valence and quadruple zeta valence quality for $\mathrm{H}$ to $\mathrm{Rn}$ : Design and assessment of accuracy, Physical Chemistry Chemical Physics. 7 (2005) 3297. doi:10.1039/b508541a. 
[12] S. Kawauchi, L. Antonov, Description of the Tautomerism in Some Azonaphthols, Journal of Physical Organic Chemistry. 26 (2013) 643-652. doi:10.1002/poc.3143.

[13] Y. Manolova, V. Kurteva, L. Antonov, H. Marciniak, S. Lochbrunner, A. Crochet, K.M. Fromm, F.S. Kamounah, P.E. Hansen, 4-Hydroxy-1-naphthaldehydes: proton transfer or deprotonation, Physical Chemistry Chemical Physics. 17 (2015) 10238-10249. doi:10.1039/C5CP00870K.

[14] Y. Manolova, H. Marciniak, S. Tschierlei, F. Fennel, F.S. Kamounah, S. Lochbrunner, L. Antonov, Solvent control of intramolecular proton transfer: is 4-hydroxy-3-(piperidin-1ylmethyl)-1-naphthaldehyde a proton crane?, Physical Chemistry Chemical Physics. 19 (2017) 7316-7325. doi:10.1039/C7CP00220C.

[15] J. Tomasi, B. Mennucci, R. Cammi, Quantum Mechanical Continuum Solvation Models, Chemical Reviews. 105 (2005) 2999-3094. doi:10.1021/cr9904009.

[16] R. Improta, UV-Visible Absorption and Emission Energies in Condensed Phase by PCM/TDDFT Methods, in: V. Barone (Ed.), Computational Strategies for Spectroscopy, John Wiley \& Sons, Inc., Hoboken, NJ, USA, 2011: pp. 37-75. doi:10.1002/9781118008720.ch1.

[17] L. Antonov, S. Kawauchi, Y. Okuno, Prediction of the color of dyes by using timedependent density functional theory, Bulgarian Chemical Communications. 46 (2014) 228237.

[18] D. Jacquemin, B. Mennucci, C. Adamo, Excited-state calculations with TD-DFT: from benchmarks to simulations in complex environments, Physical Chemistry Chemical Physics. 13 (2011) 16987. doi:10.1039/c1cp22144b.

[19] K. Wolinski, J.F. Hinton, P. Pulay, Efficient implementation of the gauge-independent atomic orbital method for NMR chemical shift calculations, Journal of the American Chemical Society. 112 (1990) 8251-8260. doi:10.1021/ja00179a005.

[20] J.R. Cheeseman, G.W. Trucks, T.A. Keith, M.J. Frisch, A comparison of models for calculating nuclear magnetic resonance shielding tensors, The Journal of Chemical Physics. 104 (1996) 5497-5509. doi:10.1063/1.471789.

[21] S. Hristova, S. Angelova, P.E. Hansen, L. Antonov, 4-Carboxyl-2,6dinitrophenylazohydroxynaphthalenes tautomerism NMR re-explained and other methods verified, Dyes and Pigments. 142 (2017) 226-229. doi:10.1016/j.dyepig.2017.03.037.

[22] M. Kline, D. Pierce, S. Cheatham, Assignment of oxime and hydrazone configuration using ${ }^{1}$ $\mathrm{H}-{ }^{15} \mathrm{~N}$ and ${ }^{13} \mathrm{C}-{ }^{15} \mathrm{~N}$ coupling measurements at natural abundance: Assignment of oxime and hydrazone configuration, Magnetic Resonance in Chemistry. 55 (2017) 154-156. doi:10.1002/mrc.4536.

[23] M. Kasha, Energy Transfer Mechanisms and the Molecular Exciton Model for Molecular Aggregates, Radiation Research. 20 (1963) 55-70.

[24] M. Kasha, H.R. Rawls, M. Ashraf El-Bayoumi, The exciton model in molecular spectroscopy, Pure and Applied Chemistry. 11 (1965). doi:10.1351/pac196511030371.

[25] L. Antonov, G. Gergov, V. Petrov, M. Kubista, J. Nygren, UV-Vis spectroscopic and chemometric study on the aggregation of ionic dyes in water, Talanta. 49 (1999) 99-106. doi:10.1016/S0039-9140(98)00348-8. 
Highlights:

- The title compound exists as two isomers in dimethyl sulfoxide.

- $15 \mathrm{~N}$ NMR approach is able distinguish them.

- The aggregation of the $E^{\prime}$ isomer is proven by $\mathrm{X}$-ray analysis. 